\title{
Ecological consequences of primary and secondary seed dispersal on seed and seedling fate of Dipteryx oleifera (Fabaceae)
}

\author{
Javier Ruiz ${ }^{1,3}$, Douglas H. Boucher ${ }^{2}$, Luis F. Chaves ${ }^{1}$, Cherryl Ingram-Flóres ${ }^{3}$, Delvis Guillén ${ }^{4}$, \\ René Tórrez ${ }^{4} \&$ Oscar Martínez ${ }^{4}$ \\ 1. Department of Ecology and Evolutionary Biology, University of Michigan, Ann Arbor, MI 48109; jeruiz@umich.edu, \\ lfchaves@umich.edu \\ 2. Union of Concerned Scientists, 1825 K Street, NW, Washington, DC 20006-1232, USA; dboucher@ucsusa.org \\ 3. Programa Científico Complementario, Villa Venezuela, Grupo I-4661, Managua, Nicaragua; cheinflor@hotmail.com, \\ javierruizphd@gmail.com \\ 4. Universidades de las Regiones Autónomas de la Costa Atlántica de Nicaragua, Bluefields, Nicaragua.
}

Received 03-VIII-2009. C Corrected 19-II-2010. Accepted 22-III-2010.

\begin{abstract}
The relative contributions of primary and secondary seed dispersal to plant demography have received little investigation. Evidence on these seed dispersal types, on seed fate and seedling recruitment of the tropical rain forest tree Dipteryx oleifera, is presented. The study was conducted in a 6.37 ha permanent plot where seeds and seedlings were located and tagged for the 2007 cohort. A total of 2814 seeds were threaded and their fate was followed one year after germination. Primary seed dispersal by bats protected seeds from insect larval predation below the adult tree. Bats congregated seeds in bat seed piles located at a mean distance of $40.94 \pm 1.48 \mathrm{~m}$ from the nearest adult individual of $D$. oleifera. Terrestrial vertebrates congregated seeds in caches located $41.90 \pm 2.43 \mathrm{~m}$ from the nearest adult individual of $D$. oleifera. The results of the fitted proportional hazard model suggested that primary seed dispersal decreased seed hazard probability by $1.12 \%$ for each meter from the adult conspecific $(p<0.001)$ and that secondary seed dispersal decreased it by $23.97 \%(p<0.001)$. Besides, the odds ratio regression models results showed that the overall effect of unviable seeds was a reduction in viable seed predation rate. For each unviable seed deposited by bats into the seed piles, the rate of seed predation by terrestrial vertebrates decreased $6 \%(\mathrm{p}<0.001)$. For each damaged seed by terrestrial vertebrates in the seed piles, the rate of germination decreased $4 \%(p<0.001)$. For each germinated seed in the seed piles, the rate of recruitment increased $16 \%(\mathrm{p}=0.001)$. Seedling survival of seeds that emerged after secondary seed dispersal events, showed no statistically significant difference in arthropod herbivory, in relation to seedlings that came from seeds that were dispersed only primarily by bats $(\mathrm{F}=0.153, \mathrm{p}=0.697, \mathrm{df}=1.98)$. Thus both primary and secondary dispersal contributed to higher seedling survival away from the nearest adult D. oleifera $\left(\mathrm{r}^{2}=0.713, \mathrm{n}=578, \mathrm{p}=0.004\right)$. The distribution of D. oleifera seedlings is consistent with the Janzen-Connell Hypothesis and depends on primary dispersal by bats, secondary dispersal by terrestrial vertebrates, a seed masking effect and, the constant threat of insect herbivores on seedlings. Rev. Biol. Trop. 58 (3): 991-1007. Epub 2010 September 01.
\end{abstract}

Key words: unviable seeds, seed masking, seedling demography, arthropod herbivory, Nicaragua.

Seed dispersal away from the seed source can be fundamental for plant demography (Howe \& Miriti 2004). Higher density of conspecific seeds and seedlings near adult trees correlates with disproportionately higher damage by granivores (Howe \& Smallwood
1982), herbivorous arthropods (Clark \& Clark 1985) or pathogens (Augspurger 1983) than seedlings further away from adults, where both seedlings and their natural enemies are at lower densities. This idea is known as the JanzenConnell Hypothesis (Janzen 1970, Connell 
1971), which considers the distance effect that occurs when seeds are moved away from the high density conditions, and where both seeds and seedlings escape damage. Although it is fundamentally important to understand the effect of density and distance on survival, an aspect that has received little investigation is the measurement of the relative contributions of primary versus secondary seed dispersal to plant demography (Vander Wall et al. 2005), the focus of this study. Primary seed dispersal occurs when seeds fall below the adult tree by gravity, or are dispersed away by birds or flying mammals. Secondary dispersal occurs when seeds are moved in the forest understory after primary seed dispersal.

Field research has showed that there is minimal evidence about the relative contribution of dispersal mechanisms on seed and seedling demography (Howe \& Miriti 2000, 2004). The reasons for this shortcoming have been due, to a large extent, to the misunderstanding about what is and what is not seed dispersal (Vander Wall et al. 2005). Whenever secondary seed dispersal was effectively measured, the ecological consequences on plant demography have been reported as positive (Forget 1990, Moore 1997, DeMattia et al. 2004, Russo 2005). For example, terrestrial vertebrate secondary seed dispersal of Vouacapoua americana (Legumonisae) (Forget 1990) and Virola calophylla (Myristicaceae) led to higher seedling survival than below the adult conspecific trees or below spider monkey sleeping sites where seed densities were higher (Russo 2005). In a field study the effect of seed abundance and size of Carapa procera (Meliaceae) on the distance that seeds were moved by secondary dispersal was examined. Results suggest that secondary seed dispersal distance is greater during years of low seed abundance although seedling recruitment was higher during highly productive years. Larger seeds were most frequently moved by red acouchy (Myoprocta acouchy) during years of low seed production (Janzen et al. 2004).

In this study we aim to understand how secondary seed dispersal could enhance seed and seedling survival. Specifically, we explored whether the production of unviable seeds congregated by bats below roosting sites could enhance secondary seed dispersal, seed survival and thus seedling recruitment away from the nearest conspecific Dipteryx oleifera tree. We predict that the presence of unviable seeds will "confuse" terrestrial vertebrates, which would have to spend time and effort locating viable seeds, thus leading to reduced seed predation of viable seeds, which would have a greater chance of survival. Later, after removing viable seeds from seed piles throughout the forest floor, those terrestrial vertebrates may forget the location of removed viable seeds (Boucher 1981), thus resulting in higher recruitment rate away from the seed piles. This seed "masking" effect would largely determine the degree of plant recruitment, arthropod herbivory and seedling distribution with respect to the nearest conspecific adult tree.

In other words, we seek evidence to test the general hypothesis: Seed and seedling survival probability of $D$. oleifera increase after both bat seed dispersal and terrestrial vertebrate seed dispersal away from the nearest conspecific adult, because there seed predation and arthropod herbivory are lower. This general hypothesis will be evaluated through several specific hypotheses: 1) If viable seeds are masked among unviable ones at the bat seed piles then seed survival is increased in piles with a higher number of unviable ones. 2) The relative effect of secondary seed dispersal on seed and seedling stages is higher than if the seed would have been only primarily dispersed (Howe \& Miriti, 2000, 2004). 3) If seedling density is lower away from the adult tree it makes it harder for herbivorous arthropods to locate seedlings, which would reduce herbivory.

\section{MATERIALS AND METHODS}

Study site: The research was conducted in a tropical rain forest in eastern Nicaragua from April 2005 to April 2007 at the site known as La Unión $\left(12^{\circ} 05^{\prime} \mathrm{N}, 83^{\circ} 55^{\prime} \mathrm{W}\right.$, elevation 
10-20m.a.s.1., mean annual temperature $=26^{\circ} \mathrm{C}$, mean annual precipitation $=5000 \mathrm{~mm}$ ) (IRENA 1991). The study was conducted within a 6.37ha plot established in 2002. During 2006 we mapped and followed the fate of 2814 seeds as they appeared within a 3.2ha subplot. The forest is accessible by the Caño Negro River where we have worked since 1994. The study area is within a primary forest recovering after the damage by hurricane Joan in 1988 (Granzow-de la Cerda et al. 1997). The area corresponding to primary forest is about $50 \mathrm{ha}$ connected to a swamp forest of about $200 \mathrm{ha}$.

D. oleifera system: This is an excellent system to study the consequences of primary and secondary seed dispersal on plant recruitment because we know many details of its dispersal ecology (Clark \& Clark 1984, 1987, 1992, Clark et al. 1993, Forget 1990, 1992, Ruiz et al. 2009b). Fruits are large elliptical almond-like drupes of approximately $6 \times 4 \mathrm{~cm}$, generally dispersed by bats (e.g. Artibeus jamaicensis, Artibeus lituratus) (Bonaccorso et al. 1980) and terrestrial vertebrates (i.e. squirrels, agoutis, pacas, etc.) (Asquit et al. 1999, Cintra \& Horna 1997, Forget \& Milleron 1991, Forget 1992, 1993).

Dipteryx oleifera also known as Dipteryx panamensis, is a Neotropical canopy emergent tree common in the lowlands. It can reach heights of $50 \mathrm{~m}$ and diameter at breast height (DBH) of about $1500 \mathrm{~mm}$ (Clark \& Clark 1992). D. oleifera is a large seeded species with heavy fruits averaging $25.2 \mathrm{~g} \pm 4.4 \mathrm{SD}$, $\mathrm{n}=80$ (unpublished data) and it is nondormant (Sautu et al. 2006). This species has an embryo protected within a hard ectocarp, which makes threading approaches suitable for evaluating seed dispersal, seed predation and seedling recruitment. For the rest of this paper we will refer to the fruit as "seed," since "seed" is the term generally used when referring to diaspores in studies exploring dispersal and recruitment dynamics of tropical tree species (Vander Wall et al. 2005). There are 14 adult individuals of D. oleifera within the 6.37 ha plot. In a previous field study we found that $D$. oleifera trees are slightly clumped in the northern side of the plot; the spatial distribution of seeds and seedlings is clumped (Ruiz et al. 2009b). Seed and seedling clumps are generally located below the adult trees or else far away from the nearest conspecific adult. Seedling survival increases with the distance to the nearest conspecific adult tree, where seedling herbivory is lower (Ruiz et al. 2009b).

D. oleifera is primarily dispersed by bats and secondarily dispersed by non-flying vertebrates. Primary dispersal occurs when seeds fall from the crown of the tree to the forest floor or when bats move the seed to bat feeding roosts. Bats are defined as primary dispersers because they pick the fruits off the tree and not off the ground. Secondary seed dispersal occurs when seeds are moved on the forest floor by terrestrial vertebrates, which scatter seeds or congregate them in small seed piles named "caches" or even bury seeds into the forest floor (Forget \& Milleron 1991, Jansen et al. 2006).

Bat trapping assessment: Two mist nets ( $12 \times 2 \mathrm{~m}$ and $8 \times 2 \mathrm{~m}$, respectively) were used to trap bats. The mist nets were placed in open areas approximately $3 \mathrm{~m}$ above the forest floor. Below the mist nets we placed a plastic cover of the same dimensions on the ground in order to collect seeds dropped by bats once they hit the mist nest. Bat taxonomical determination was carried out by Jason Beck and Stephanie Leslie from Southern Utah University. The bat species trapped over the research period were Artibeus intermedius, Artibeus jamaicensis, Artibeus lituratus, Artibeus phaeotis, Artibeus watsoni, Carolia castanea, Carolia perspicillata, Chiroderma villosum, Myotis nigricans, Phyllostomus discolor, Trachops cirrhosus, Vampyressa nymphaea, Glossophaga soricina and Hylonycteris underwoodi. Bats of the genus Artibeus are potential seed dispersers, since their size would allow them to move the large seeds of $D$. oleifera.

Terrestrial vertebrates trapping assessment: Terrestrial vertebrate trapping success has been extremely low in the research area, 
as is frequently observed in studies at lowland rain forests (McClearn et al. 1994). In order to trap terrestrial vertebrates we used Sherman traps $(7 \times 16 \mathrm{~cm})$ and Tomahawk traps $(16 \times 60 \mathrm{~cm})$. A total of 100 "Sherman traps" and 60 "Tomahawk traps" were systematically set up within the research plot from April to May 2005. We used the grid system to place traps spaced from each other for approximately $10 \mathrm{~m}$. The traps were moved each week to another section within the plot until the whole area was censused. Once the traps were set up we searched for terrestrial vertebrates each morning for a week. Each trap was set up near to fallen trunks at the base of trees or near to holes in the ground, because these sites are used by terrestrial vertebrates as routes or rest sites. Seeds of D. oleifera, Welfia regia and Bactris gasipaes were used as bait because these seeds were abundant during the period of the trapping assessment; the bait was replaced as necessary. We used a field guide to the mammals of Costa Rica (LaVal \& Rodriguez 2002) and Central America (Reid 1997) in order to carry out taxonomical determinations in situ. After identification, terrestrial vertebrates were returned to the forest floor. To date, species captured by the trapping fieldwork at the La Union site are: Proechimys semispinous, Oryzomys spp., and Nyctomys sumichirasti (Rodentia) and Marmosa mexicana, Didelphis virginiana and D. alventris (Marsupialia). We use tracks and footprints to identify larger potential seed dispersers, because traps used were not large enough to catch agoutis and pacas. The total trapping success was approximately $3 \%$.

Seed fate assessment: In order to evaluate seed fate we threaded and mapped seeds as these appeared within a 3.2ha subplot from January 2006 to July 2006. A micro precision nylon thread (Imperial Thread Inc. ${ }^{\mathrm{TM}}$, Northbook, Illinois), was super-glued to all seeds found within this area. The thread consists of a microfiber attached to each seed. Whenever terrestrial vertebrates moved seeds the thread came out the bobbin, which was secured to the forest floor with a plastic toothpick. The distance from the bobbin to the new location of the seed is defined as the secondary seed movement distance. Each bobbin was assigned a unique number in order to follow individual records. Previous studies have only evaluated the effect of seed removal, as pointed out in a review of the literature on seed dispersal (Vander Wall et al. 2005). The seed threading approach allowed us to follow seed movements and ultimately to determine seed predation, germination, and seedling recruitment events (Witt 2001, DeMattia et al. 2004, Forget \& Wenny 2005). We used the threading procedure developed earlier by Witt (2001) to account for the fate of thousands of seeds. When eaten seeds were found we did not thread them, although we did measure their position. Seed conditions were measured at least once each month for a period of eight months. Seed conditions were classified as: predated, unviable (when threaded but with undeveloped endosperm) (Fig. 1), germinated and seedling recruits $(>1$ year after germination).

Bat seed piles and seed conditions below roosting palms: Seeds of D. oleifera at bat seed piles and caches were systematically located during the censuses in 2006. Bat seed piles were generally found below bat roosting palms with either bat faeces or marks of manipulation by bats. For example, endocarps (hard valves) were left only partially covered with the fleshy membrane that bats eat (mesocarp). Cached seeds had been longer on the forest floor. For example, seeds had bare endocarp, without vestiges of the mesocarp and endocarp coloration was darker than piled seeds. Early during
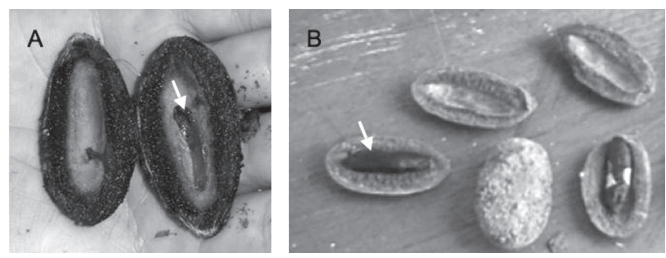

Fig. 1. (A) Seed with undeveloped endosperm (unviable seed) and (B) seed with developed endosperm (viable seeds) (Photos: Javier Ruiz). 
the seed production season we noticed that a considerable proportion of seeds were unviable. We used pocket-knives to split the seed's valves and determined whether seeds were unviable after the time period that seeds need to germinate ( $\sim 17$ days). Unviable seeds did not have embryo, or the embryo or the valves were undeveloped and never germinated. They were distinct from viable seeds in their physical characteristics (Fig. 1), which allowed us to precisely distinguish between these two seed conditions in the field. Also, unviable seeds were smaller, whiter and with softer endocarps than viable seeds. When seeds were moved and opened by terrestrial vertebrates, we were also able to distinguish between viable and unviable seeds by their coloration and hardness (density) of the valves.

Seed survival hazard functions: Seed survival was analyzed using a Cox proportional hazard models (Cox \& Oakes 1984). The first model tests the effects of the covariates seed dispersal mode $(\beta)$, final distance to the nearest conspecific adult tree $(\partial)$ and seed hoarding (cache and bat seed piles) $(\mu)$ on the proportional hazard regression:

$$
h_{(t)}=h_{O(t)} e^{\beta M+\partial D+\mu H}
$$

where $h_{0}$ is the baseline mortality hazard computed from the adjusted hazard function; $M$ corresponds to primary or secondary seed dispersal; and $D$ is a metric covariate, corresponding to the maximum dispersal distance from the nearest conspecific adult tree (meters). The variable $H$ codes for primary seed dispersal or secondary seed dispersal, when seeds were moved into bat seed piles or caches. Time measured as census period is $t$, and $\beta, \partial, \mu$ are the covariates of the coefficients computed above. The model was simplified by a backward process (Faraway 2005), because seed hoarding, $H$, does not have a statistically significant effect on the estimated seed hazard function:

$$
h(t)=h 0(t) e^{\beta M+\partial D}
$$

Cox proportional hazard models were used to evaluate the relative contribution of primary seed dispersal or secondary seed dispersal on seed mortality probability (formula 2 ). In one model, the effect of primary seed dispersed on seed mortality probability with respect to the nearest conspecific adult tree was analyzed. Another model, the effect of secondary seed dispersal on seed mortality probability with respect to the nearest conspecifc adult tree was evaluated. For each model, the observed proportional hazard model was evaluated through a confidence interval computed from 999 Monte Carlo replications. Mortality accounted for seed predation due to terrestrial vertebrates or a predatory larval stage of a fly of the genus Taeniaptera (Ruiz et al. 2009b), under taxonomical study by Jean-Michel Maes (Museo Entomológico de Nicaragua). Because unviable seeds were distinguished in the field these were not included in the proportional hazard model in order to meet the formulation of the model.

Seed masking assessment: We used descriptive statistics, such as the mean and standard errors in order to determine statistical differences in the seed number between seeds condition. We also estimated the mean and standard error for the distance of bat seed piles to the nearest conspecific adult tree. Data corresponding to the number of seeds and seedlings were also analyzed using generalized linear rate models (Faraway 2005), which have the following general form:

$$
\ln (Y)=\ln (Z)+\alpha X+\varepsilon
$$

In formula $3, Y$ indicates the number of positive outcomes out of $Z$ trials, $\alpha$ is a vector of parameters for the $X$ vector of predictors and $\varepsilon$ the normal error which is i.i.d. - obtained once the iterative process for fitting a Poisson Generalized Linear Model GLM is carried out. The process of fitting Negative Binomial GLMs includes the additional correction for over dispersion in the dataset (Faraway 2005). 
Here we studied the rate of predated seeds as a function of the number of unviable seeds using a Poisson GLM. Data corresponding to the number of predated seeds on germination rate were analysed using a Negative Binomial GLM, since the data was overdispersed (Faraway 2005). We used Poisson GLMs to evaluate the rate of seedling recruitment as a function of the number of germinated seeds and in another one the rate of seedling recruitment as a function of the number of unviable seeds.

Seedling demography: In order to determine whether seedling fate depends on secondary seed dispersal with respect to the nearest conspecific adult $D$. oleifera tree, we followed germination from June 2006 to April 2007. We mapped the $(x ; y)$ coordinates to each seedling within the plot. For seedlings that germinated from secondarily dispersed seeds, we also mapped their $(x ; y)$ positions. Seedlings are considered to be individuals with height $\leq 100 \mathrm{~cm}$. Maximum height is the vertical distance from the forest floor to the highest green tissue. An aluminum tag with a unique number was looped around the stem of each seedling as these were found.

Seedling herbivory assessment: In order to determine the effect of arthropod herbivory on seedling recruitment dynamics a digital photograph of the leaves of each seedling was taken from above the seedling canopy. Leaf area damaged by herbivory was evaluated from digital photographs taken in early January of 2005 and 2006. Leaflets of D. oleifera are remarkably horizontal which allowed us to visually count the percentage of herbivory per leaflet. Leaf area damage per leaflet was summed up and divided by the total number of leaflets in order to assess the percentage of herbivory per seedling. To determine the accuracy of the visual estimation, leaf damage was also measured using a grid on 100 seedlings. There was no significant statistical difference between the methods, allowing us to use the faster method of visual estimation. This insect herbivore damage to leaflets consisted largely of holes in the interior as well as at the edges of the leaflets.

\section{RESULTS}

Seed fate: The total number of seeds sampled was 2814 , out of this total $848(30.13 \%)$ were dispersed below the adult $D$. oleifera tree by gravity. There were 575 seeds in a census of 60 bat seed piles and 277 seeds in a census of 32 caches, the percentage of unviable seeds at both seed pile types is $8.03 \%$. There was no statistical difference in the mean number of seeds between bat seed piles and caches (Fig. 2 ). The number of predated seeds was about twice larger than unviable or germinated seeds; about $70 \%$ of these seeds at seed piles were predated. The mean distance of seed piles from nearest adult $D$. oleifera was $41.90 \pm 2.43 \mathrm{~m}$ (SE) for caches and $40.94 \pm 1.48 \mathrm{~m}$ (SE) for bat seed piles. Primary seed dispersal mean distance to nearest $D$. oleifera adult individual was $23.77 \pm 0.47 \mathrm{~m}$ (SE) and secondary seed dispersal mean distance to the nearest $D$. oleifera was $24.40 \pm 0.14 \mathrm{~m}$ (SE). Secondary seed dispersal was frequent away from the nearest adult $D$. oleifera tree (Fig. 3), although mean secondary seed movement is approximately $1.5 \mathrm{~m}$ (this is the distance that seeds were moved by terrestrial vertebrates from the place where the seed was first labelled with the thread). The proportional hazard model fitted to the seed data set shows that for each meter away from the nearest adult tree of $D$. oleifera the probability of seed damage, decreased by $1.12 \%$. Secondary seed dispersal decreases the probability of seed damage by $23.97 \%(p<0.01$, Table 1$)$. Figure 4 shows a statistically significant higher seed mortality probability for seed that were only primarily dispersed than for seeds that were further dispersed by secondary means up to $65 \mathrm{~m}$ with respect to the nearest conspecific adult tree. At further distances with respect to the conspecific adult tree this difference is not statistically significant.

Seed fate with respect to bat roosts: For each additional unviable seed deposited by 


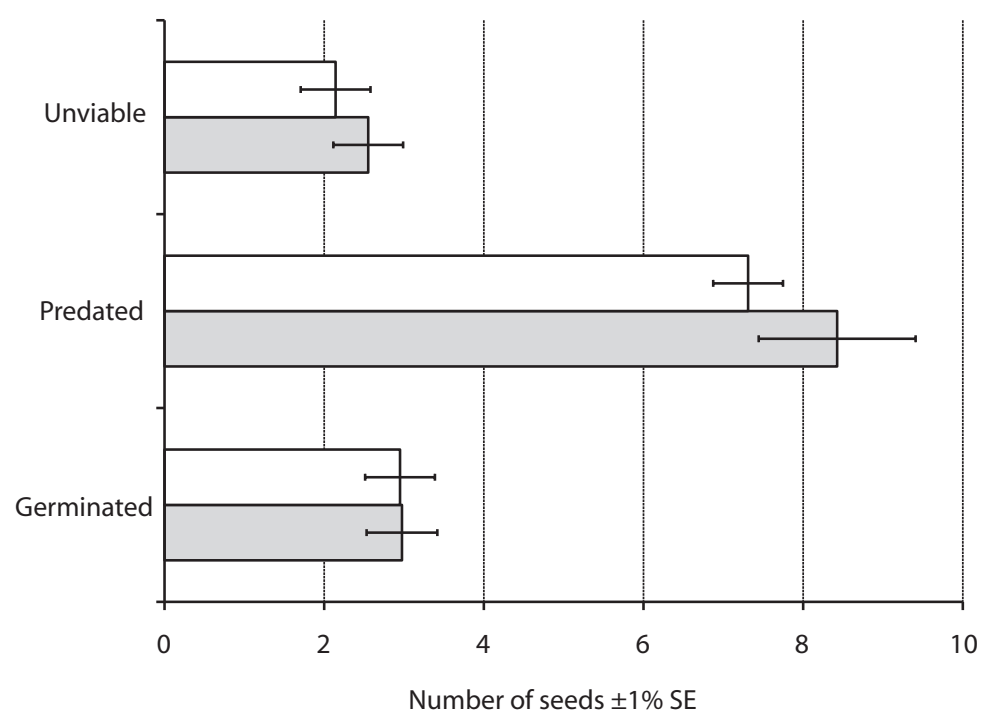

Fig. 2. Mean number of seeds per bat roost and cache per each seed fate. Error bars are 1\% standard error of the mean per seed congregation (bat roost - white bars or cache shaded bars).

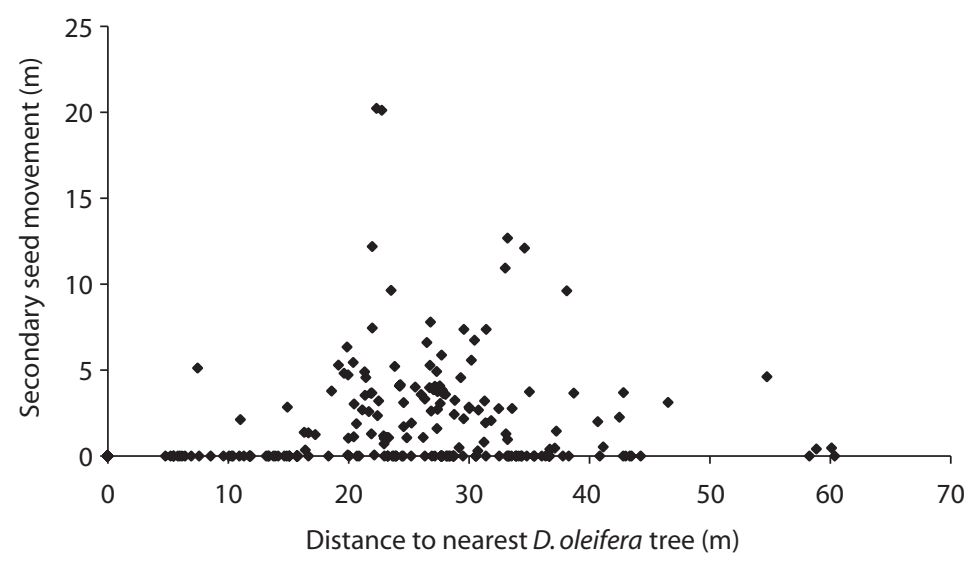

Fig. 3. Secondary seed movement $(\mathrm{m})$ as a function of the distance to nearest conspecific adult tree. $X$-axis represents primary seed dispersal or distance to nearest conspecific adult tree and $Y$-axis represents seed secondary movement $(\mathrm{m})$. The boxed area within the dashed lines indicates distance where secondary seed movements are frequent (for fields methods).

the bats, the rate of seed predation decreased $6 \% \quad(\mathrm{p}<0.001$, Table 2$)$. For each predated seed at the seed pile seed germination rate decreased 4\% $(\mathrm{p}<0.001$, Table 2$)$. For each additional germinated seed from the seed pile the rate of seedling recruitment is increased $16 \%(\mathrm{p}=0.000$, Table 2$)$. However, the effect of unviable seed on the rate of seed recruitment was not significant (Table 2).

Seed pile dynamics and seedling fate: Seedling survival increased with distance from the nearest $D$. oleifera adult $\left(\mathrm{r}^{2}=0.713\right.$, $\mathrm{n}=578, \mathrm{p}=0.004$, Fig. 5), and this relationship 
TABLE 1

Results of the Proportional Hazard Ratio Model for seeds of D. oleifera in response to the effect of granivores

$\begin{array}{lccccccc}\text { Factor } & \text { Coef. } & \begin{array}{c}\text { Exp } \\ \text { (Coef.) }\end{array} & \begin{array}{c}\text { SE } \\ \text { (Coef.) }\end{array} & \text { Z } & \begin{array}{c}\text { Lower } \\ \text { CI 95 \% }\end{array} & \begin{array}{c}\text { Upper } \\ \text { CI 95 \% }\end{array} & \text { P } \\ \text { Distance to nearest conspecifc } & -0.012 & 0.988 & 0.002 & -6.33 & 0.985 & 0.992 & 2.40 \text { E-10 } \\ \text { Dispersal mode } & -0.274 & 0.761 & 0.082 & -3.33 & 0.647 & 0.894 & 8.80 \text { E-04 }\end{array}$

The hazard (mortality) probability is evaluated as a dependent variable of two factors, distance to nearest conspecific tree and dispersal mode (primary or secondary dispersal). coef $=$ coefficient and $\exp (\mathrm{coef})$ is the exponent of the coefficient of the model with its respective standard error estimate represented as se (coef).

$\mathrm{z}=$ value of the $\mathrm{z}$ test. Lower .95 is the lower bound of the confidence envelops and upper .95 is the upper bound of the confidence interval. $\mathrm{P}=$ statistic probability of $\mathrm{Z}$. The hazard (mortality) coefficient in the first column is 1 -exp (Coef.)*100, 1.12 and $23.97 \%$ respectively

$\mathrm{n}=2814$

Rsquare $=0.018(\max$ possible $=0.955)$

Likelihood ratio test $=50.2$ on $2 \mathrm{df}, \mathrm{p}=1.26 \mathrm{e}-11$

Wald test $=47.7$ on $2 \mathrm{df}, \mathrm{p}=4.34 \mathrm{e}-11$

Score $($ logrank) test $=48.4$ on $2 \mathrm{df}, \mathrm{p}=3.07 \mathrm{e}-11$

accounted for $71 \%$ of the variance in seedling distributions with respect to the nearest conspecific adult of $D$. oleifera. Seedling fate was not different between seed pile types $\left(X^{2}=0.61\right.$, $\mathrm{df}=1, \mathrm{p}=0.435) ; 17$ out of 43 seedlings dispersed from caches survived and 25 out of 90 seeds dispersed from bat seed piles survived one year after germination. There was a statistically significant difference in the number of surviving seedlings after primary seed dispersal versus seedlings surviving after secondary dispersal one year after germination $\left(X^{2}=12.62\right.$, $\mathrm{df}=1, \mathrm{p}=0.001)$; we found that 64 out of 136 seedlings survived when dispersed by primary means alone and only 27 out of 111 seedlings survived after secondary dispersal.

Seedling fate and relation to herbivory: Arthropod herbivory damage followed a negative function with respect to the distance to the nearest adult D. oleifera individual $\left(\mathrm{r}^{2}=0.29\right.$, $\mathrm{n}=112, \mathrm{p}=0.059$, Fig. 6). Seedling survival of those that emerged after secondary seed dispersal events showed no statistically significant difference in arthropod herbivory in relation to seedlings that came from seeds that were dispersed only primarily by bats $(\mathrm{F}=0.153$, $\mathrm{p}=0.697, \mathrm{df}=1.98$ ).

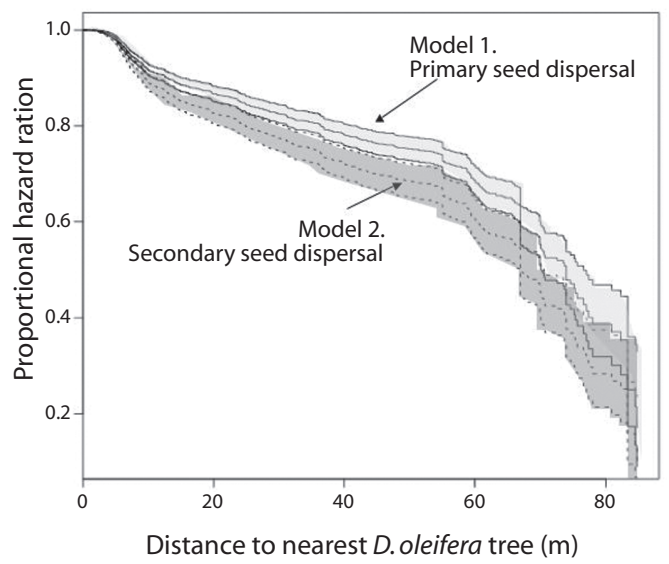

Fig. 4. Proportional hazard ratio as a function of the distance to the nearest conspecific adult tree. Model 1 . Evaluates the effect of primary seed dispersal and model 2 the effect of secondary seed dispersal. Line at the middle of each shaded area represents the mean proportional hazard ratio computed from the field data and the two lines next to it are the confidence intervals computed after 999 bootstrap assignments.

\section{DISCUSSION}

Secondary seed dispersal was more effective than primary dispersal in releasing seed from negative density dependent effects 
TABLE 2

Proportion of seed and seedling fate of $\mathrm{D}$. oleifera in response to the number of unviable seeds, the number of germinated seeds and the number of predated seeds at seed piles

$\begin{array}{cccccc}\text { Model } & \text { Direction and type of effect } & \text { Predictor } & \text { Dep. Var. } & \text { Rate of Dep. Var. (95\% CI) } & \text { Wald Z } \\ & \text { BC } & & & 1 & - \\ \text { a. } & \text { U-o P } & \text { NU } & \text { P } & 0.94(0.91 ; 0.97) & -3.486^{*} \\ \text { b. } & \text { P -o G } & \text { NP } & \text { G } & 0.96(0.94 ; 0.99) & -2.740^{*} \\ \text { c. } & \text { G } \rightarrow \text { R } & \text { NG } & \text { R } & 1.16(1.10 ; 1.23) & 0.000^{*} \\ \text { d. } & \text { U } \rightarrow \text { R } & \text { NU } & \text { R } & 1.08(0.97 ; 1.19) & 0.1580\end{array}$

Letters represent the direction and type of effect of unviable seeds on predation (UP); seed predation on germination (PG); germination on seedling recruitment (GR) and effect of unviable seeds on seedling recruitment (UR). BC=1, is the baseline of comparison for Poisson generalized linear models GLMs and Negative binomial model GLM. Rate corresponds to the effect of either (U, P or G) on corresponding (P, G, R), second column.

$*(\mathrm{P}<0.005)$

"-o" represents negative effects

" $\rightarrow$ " represents positive direct effects

" $\rightarrow$ " represents positive indirect effect

$\mathrm{B}=$ bat seed piles, $\mathrm{NU}=$ unviable seeds, $\mathrm{NP}=$ predated seeds, $\mathrm{NG}=$ germinated seeds, Dep. var=dependent variable

a. $\left(\right.$ Goodness of fit: $\left.\mathrm{chi}^{2}=85.55, \mathrm{df}=85, \mathrm{P}>0.46\right)$

b. (Dispersion parameter DP $[ \pm$ S.E. $]=2.41 \pm 0.90$; GF: chi $^{2}=91.92, \mathrm{df}=84, \mathrm{P}>0.26$ )

c. (Goodness of fit: chi $^{2}=65.42, \mathrm{df}=86, \mathrm{P}=3.048 \mathrm{e}-07$ )

d. (Goodness of fit: chi $^{2}=89.84, \mathrm{df}=85, \mathrm{P}>0.18$ )

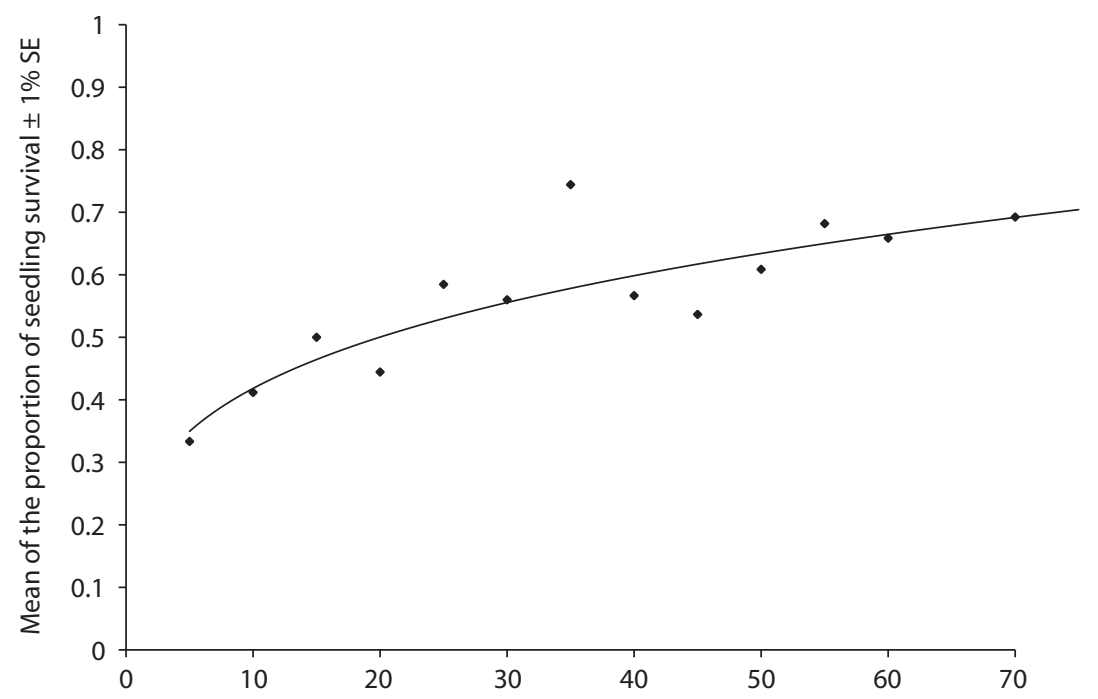

Distance to nearest $D$. oleifera tree $(\mathrm{m})$

Fig. 5. Mean seedling survival as a function of the nearest conspecific adult D. oleifera tree. 


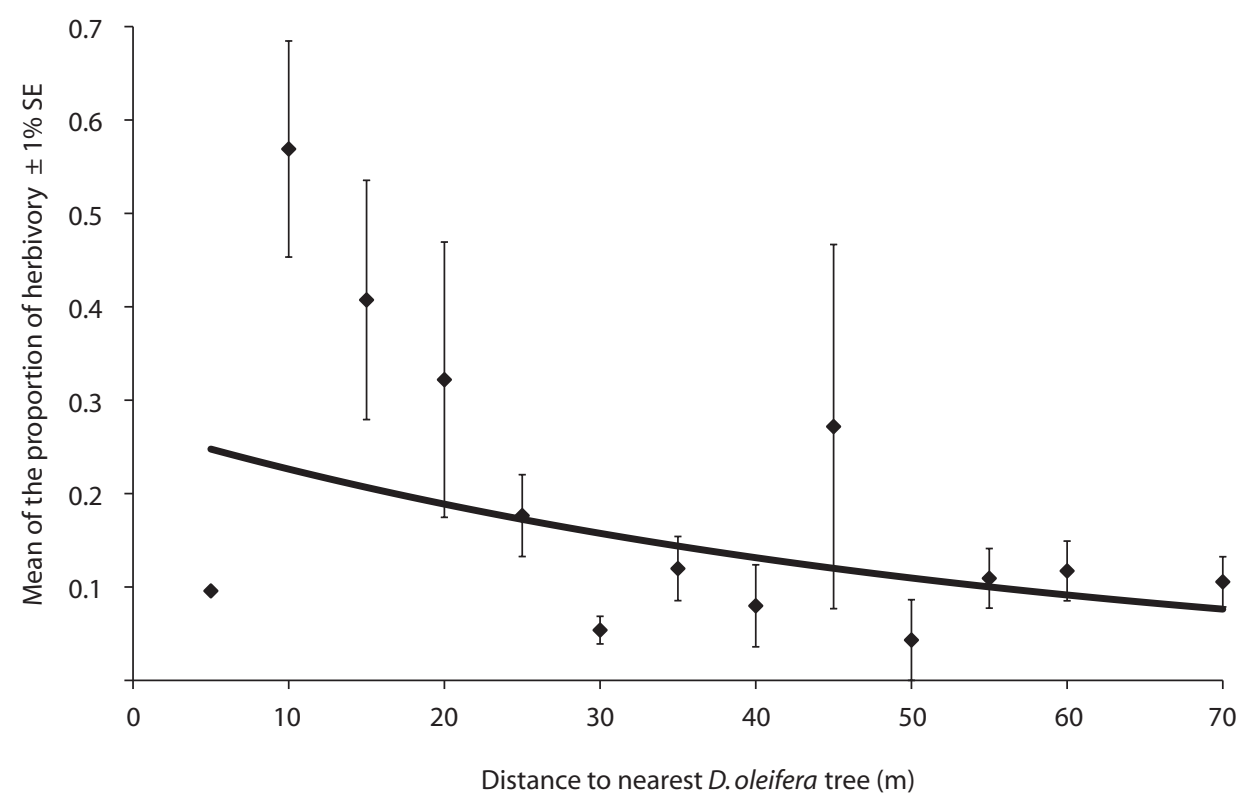

Fig. 6. Mean arthropod herbivory proportion as a function of the nearest conspecific adult $D$. oleifera tree. Error bars are the $1 \%$ standard errors computed per each $5 \mathrm{~m}$.

associated to the nearest conspecific $D$. oleifera tree. First, we tested the hypothesis: seed dispersal reduce the probability of seed mortality with respect to the distance to the nearest conspecific $D$. oleifera tree. The results showed that the probability of seed predation decreased with the distance to the nearest conspecific adult tree, and the effect of secondary dispersal was higher up to $65 \mathrm{~m}$ from the tree. We concluded that secondary seed dispersal is necessary for seedling survival. Second, we present evidence in favour of the seed-masking effect acting on seed and seedling survival away from conspecific D. oleifera trees, on the bat seed piles. Specifically, we gathered evidence addressing the hypothesis: if seed predation rate is independent of the number of unviable seeds at bat seed piles, then there is no evidence for a seed-masking effect. The results showed that seed predation rate decreased as a function of the number of unviable seeds. Other results were not unexpected for instance, seed predation reduced seed germination and seed germination increased seedling recruitment rate, both results were strongly statistically significant. We also evaluated the hypothesis that seedling recruitment rates are independent of the number of unviable seeds at the seed piles; i.e. that there is no seed-masking effect on seedling recruitment. There is a trend suggesting that unviable seeds at the bat seed piles increased seedling recruitment (Fig. 7). Third, if seedlings escape arthropod herbivory then higher seedling survival correlates with lower insect herbivory away from the nearest $D$. oleifera tree. Seedling herbivory decreased with distance to the adult tree, mainly because after bat seed dispersal and terrestrial vertebrate seed dispersal, seedlings were present at lower densities away from these adult trees.

Seed dispersal and seed fate: The evidence presented here is in favor of the distance and density predictions of the Janzen-Connell Hypothesis. For the distance effect, we observed that $\sim 30 \%$ of the seed production, based on the 


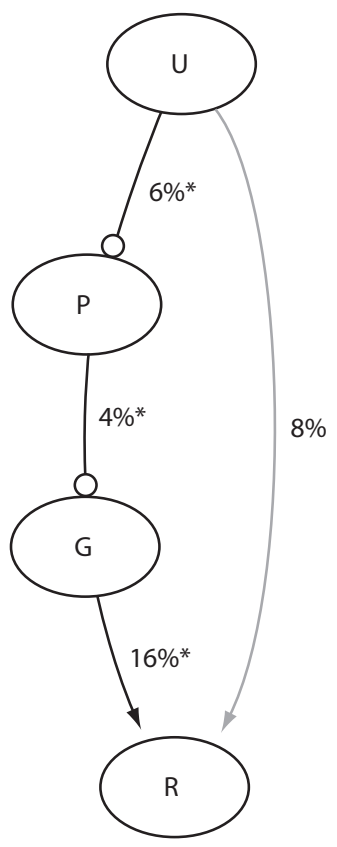

Fig. 7. Pathway diagram of the seed fate of D. oleifera; $\mathrm{U}=$ unviable seeds, $\mathrm{P}=$ predated seeds, $\mathrm{G}=$ germinated seeds and $\mathrm{R}=$ seedling recruitment. Lines with open circles represent negative direct effects, arrows represent positive direct effects and grey represents indirect effect. The sign “-o" represents negative effects, " $\rightarrow$ " represents positive effects and, " $\rightarrow$ ” represents indirect positive effect.

proportion of all seeds that were found on the ground, was dispersed below the adult tree by gravity. Remarkably, we did not observe terrestrial vertebrates moving seeds from below the adult tree (Fig. 3). This pattern in the activity of terrestrial vertebrates was also noticed in a field study conducted on Barro Colorado Island in Panama (Forget 1993), perhaps because they try to avoid their natural enemies present near adult trees of $D$. oleifera (i.e. boa constrictors and owls). For instance, field observations suggest that predation on bats (Boinski \& Timm 1985) and small terrestrial vertebrates (Becker et al. 1985) can be higher near their feeding sites. Since seeds remained at high density below adult trees this condition might have led to higher rates of seed damage by insect larvae. Insect larvae of the genus Taeniaptera (Diptera) developed in the decomposing exocarp and destroyed the endosperm during the first stage of germination. This type of seed predation accounted for approximately $90 \%$ of the observed proportional hazard ration values near the conspecific adult tree. About $40 \%$ of the seeds were moved away from the nearest conspecific adult (aprox. 20-40m), where the larvae stage was absent (Fig. 3). Another large number of seeds were scattered throughout the research plot by bats, which also congregated seeds below roosting sites. Terrestrial vertebrate seed dispersal was especially frequent approximately $40 \mathrm{~m}$ from the nearest conspecific adult, this distance is where most of the bat seed piles were located (Ruiz \& Boucher 2009) and where higher seedling recruitment occurs (Fig. 5) (Ruiz et al. 2009b). A recent field study provides evidence about effect of seed abundance of Carapa procera (Meliace$a e$ ) on secondary seed movement distance. The distance that seeds were cached was larger in two low productive years $($ mean $=27.7 \mathrm{~m} \pm 1.2 \mathrm{~m}$, mean $=22.0 \mathrm{~m} \pm 1.0 \mathrm{~m}$ ) than in two high productive years $($ mean $=21.0 \mathrm{~m} \pm 1.2 \mathrm{~m}$, mean $=12.7 \mathrm{~m} \pm 1.3 \mathrm{~m})$ (Janzen et al. 2004).

During years of low seed production terrestrial vertebrates have to hide seeds from competitors farther from where they are found onto the forest floor, which can lead to larger seed dispersal distances when seeds are forgotten. Results presented here for the D. oleifera population are for a high productive year. For instance, observed primary seed dispersal moved seeds $23.77 \pm 0.47 \mathrm{~m}$ (SE) and secondary seed dispersal $24.40 \pm 0.14 \mathrm{~m}$ (SE) away from the nearest $D$. oleifera. However, the mean distance of pre-existing seed piles from nearest adult $D$. oleifera was about two fold larger $(41.90 \pm 2.43 \mathrm{~m}, \mathrm{SE})$ for caches and for bat seed piles $(40.94 \pm 1.48 \mathrm{~m}, \mathrm{SE})$.

In a field study conducted at La Selva Biological Station in Costa Rica, the role of terrestrial mammal community in the process of seed movement of D. oleifera was assessed. The relative effect of small and middle-sized terrestrial vertebrates was effectively measured 
by way of using experimental cages. Results from this experiment suggest that at La Selva Biological Station there is a unaltered community of small and middle-sized terrestrial vertebrates moving seed of $D$. oleifera (AriasLe Claire 2001, Guariguata et al. 2002). Their trails showed fast seed removal, about $50 \%$ of caged and unprotected seeds during the first two months of the experiment. During this period there is a slightly statistic difference in the intensity of seed removal between small and large sized vertebrates. Protected seed from small terrestrial vertebrates levelled off during the rest of the experiment, however unprotected seeds were intensively removed by small sized terrestrial vertebrates (Guariguata et al. 2002). In another field study conducted at La Selva Biological Station seed predation was high below and away from adult trees of $D$. oleifera, seedling density trended to be higher away from the adult tree than below the crown of adult trees for D. oleifera (Hanson et al. 2006). Seedling densities were extremely low near and away form adult $D$. oleifera, thus supporting the hypothesis that seed removal is high at La Selva Biological Station. Furthermore, these results were different from those reported in a field study conducted at Barro Colorado Island in Panama, where artificial seed caches of $D$. oleifera placed at $50-100 \mathrm{~m}$ from the nearest conspecific adult presented higher seed survival ( $49 \%$ seed germination) than caches placed $>100 \mathrm{~m}$ ( $29 \%$ seed germination) toward the beginning of the study. Both treatments were placed in the less-used area of the terrestrial vertebrate's home range (Forget 1993). There was no seed or seedling survival away from artificial caches throughout the end of this study, due mainly to the foraging activity Dasyprocta punctata (agoutis) in Barro Colorado Island. Differences in the intensity and direction seed predation and seedling survival between our site in Nicaragua and Panama versus at La Selva Biological Station could be due to differences in the time when the research was conducted, which have been noticed to have an effect on terrestrial vertebrate activity (DeMattia et al. 2004). The effect of seed predatory larvae was not reported in the studies conducted in Panama or Costa Rica. Since we noticed the effect of larvae seed predation only during a year of extremely high seed production, it is possible that this type of seed damage is present at Costa Rica or Panama but has not been noticed yet. Another interesting dichotomy between our results and the finding reported by researchers in Costa Rica is the high rate of terrestrial vertebrate visitation below the crown of $D$. oleifera trees. Higher terrestrial vertebrate visitation below the adult D. oleifera could be in part due to a low density of natural enemies of terrestrial vertebrates during years of low seed production.

\section{Seed dispersal ecological dynamic:} Our field trapping assessments showed that squirrels (Sciurus richmondi) and spiny rats (Proechimys semispinous) are the principal agents of secondary seed movements. In a field study mentioned earlier seed predation and seed dispersal of $D$. oleifera was conduced by Sciurus granatensis (squirrels), Dasyprocta punctata (agoutis) and P. semispinosus (spiny rats). That study also showed that seed and seedling survival of $D$. oleifera occurs mainly due to the process of seed predator satiation (Forget 1993). In our field site in Nicaragua squirrels were observed near bat seed piles but never below the crown of adult $D$. oleifer $a$, and they might be avoiding being predated, as discussed before for bats. For instance the venomous snake (Lachesis stenophrys) was frequently observed at the base of the stems of $D$. oleifera during the research period (Fig. 3). In one occasion we were able to see a squirrel moving a seed from a bat seed pile and burring the seed into the forest floor. Similarly to the dispersal dynamic of D. oleifera, mice (Apodemus sylvaticus) disperse oak seeds Quercus robur and Q. petraea (Fagaceae) in two-steps in a European coniferous forest (Ouden et al. 2005). First, seeds were cached at short distances from the seed source - either were scattered or cached onto the forest floor or in shallow caches. Then, mice re-cached these seeds into deeper caches generally located further from 
the seed source. From previous preliminary nursery trials with $D$. oleifera seeds we know that when seeds are forgotten in shallow caches $(<5 \mathrm{~cm})$ seed survival can be high. During the seed production period of 2006 we found that all caches were in the forest floor.

Seed masking: We report evidence for the seed-masking hypothesis, since for each unviable seed deposited by bats into the seed piles the rate of seed predation by terrestrial vertebrates decreased six percent. After bat seed dispersal (primary dispersal), the fundamental problem is that seeds are still concentrated, even more than these would have been below the adult tree. Terrestrial vertebrates seed dispersal from the seed piles is necessary to release seeds from negative density dependent interactions. Terrestrial vertebrate seed dispersal occurs while terrestrial vertebrates predate some seeds but scatter others throughout the forest floor. Our observations of the seed dispersal dynamics at the seed piles have also been reported in other studies, for example in a field experiment seeds of several species escaped terrestrial vertebrate predation when removed from experimental seed piles (Witt 2001), or were forgotten by terrestrial vertebrates after scattering seeds were scattered throughout the forest floor by terrestrial vertebrates (Forget 1990). The evidence gathered also showed that terrestrial vertebrate seed dispersal is enhanced by the presence of unviable seeds at the seed pile (Fig. 7), which might have lowered search efficiency for viable seeds at the seed piles. Consequently, seedling recruitment is also due to key role of terrestrial vertebrates in scattering seeds from the bat seed piles throughout the forest floor.

Producing large numbers of unviable seeds seems a frequent phenomenon in the life of a rain forest tree species. Pollination limitation could be an important mechanism involved in the production of unviable seeds. In a field study, outcrossing occurred in a large proportion of the flowers of $D$. oleifera during low reproductive years. It is possible that competition forced bees to pollinate among flowering trees and thus increased the number of viable seeds (Perry \& Starrett 1980), what probably would not happen in years with high production of flowers, such as our study year. Pollination limitation is especially frequent in a majority of self-incompatible hermaphroditic species. For instance, in a hand pollination experiment, 24 out of $28(80 \%)$, species of lowland tropical rain forest were self-incompatible (Bawa et al. 1985).

Seedling survival: Seedling survival probability increases with the distance to the nearest D. oleifera adult (Fig. 4). This result is nothing new, since this evidence was also reported in studies conducted in Costa Rica and Panama (Clark \& Clark 1984, Clark et al. 1999, Condit et al. 1995) and for the present D. oleifera population in a previous study (Ruiz et al. 2009b). However, our research present results about the relative contribution of secondary seed dispersal on seedling recruitment away from the nearest conspecific adult tree (Fig. 3). We provide correlative evidence suggesting that secondary seed dispersal away from the adult tree could be releasing seeds and seedlings from natural enemies (Table 1). Bat seed scattering could be responsible for a large fraction of seedling survival away from the conspecific adult $D$. oleifera. However, in bat piled seeds, our results showed that seedling survival requires further secondary seed dispersal, which was necessary to release seedlings from granivory and arthropod herbivory associated to the nearest conspecific adult tree. Also, seedling survival seems to be enhanced by a positive indirect effect of the number of unviable seeds, the masking effect.

Arthropod herbivory effect on seedling recruitment: Our results showed that seedling arthropod herbivory decreased with distance to the nearest $D$. oleifera tree, and corroborate previous findings for D. oleifera (Clark \& Clark 1985, Ruiz et al. 2009b) . This trend is due to bat seed dispersal and terrestrial vertebrate seed dispersal, which lowered seedling density farther from the nearest conspecific adult. An interesting result is that, there was no difference in the level of arthropod herbivory 
between seedlings that were only scattered by bats with those that were secondarily dispersed from the bat seed piles. This result suggests that secondary seed dispersal could have lowered density effects near the seed piles, where herbivory effect is lower. In a previous field study we found that seedlings survival is correlated with levels of arthropod herbivory $<5 \%$ (Ruiz et al. 2009a). Because arthropod herbivory levels are low away from the adult tree, where seedling survival is high, we conclude that secondary seed dispersal is necessary to escape arthropod herbivory.

Assumptions and errors: We assumed that bats scattered seeds across the forest floor and below their roosting sites. However, our field observations only allow us to detect bat dispersal when seeds are transported to bat roosting sites. During the study we were not able to capture a bat individual dispersing a seed of $D$. oleifera, despite this fact we presume that $A$. jamaicensis is the principal seed disperser. Since white-faced monkey (Cebus cappuccino) and great green macaw (Ara ambiguus) were not frequently observed within the research site it is assumed that their effect on seed dispersal or seed predation is minimal. Our field observations suggest that there is no preference for particular bait, thus allowing a good estimation of the terrestrial vertebrate community. Using pocket-knives to split open seeds is an appropriate method because we preformed this operation weeks after germination time. Viable and unviable seeds were removed by terrestrial vertebrates a few days after being congregated by bat primary seed dispersal or secondary seed dispersal, thus suggesting that terrestrial vertebrates did not learn how to distinguish between seed types. Since we did not observe arthropod herbivory during the day, we think that arthropod herbivory occurs during the night. We observed that the leaf damage by ants of the genus Atta is minimal and consequently we consider that this type of damage does not contribute to seedling survival. Foliar herbivory estimation only accounts for a static evaluation of foliar insect damage. An accurate estimation of arthropod herbivory has to include the measurement of herbivory rate. A small ring around a leaflet midrib can be placed in order to estimate rates of insect foliar herbivory over time (Eichhorn et al. 2006). An advantage of the static herbivory estimation is that it allows us a faster estimation. Despite of the correlative nature of some of our results these open lines of investigation on the relative effect of primary and secondary seed dispersal and arthropod herbivory on seedling survival. We think that our results could be extrapolated to tree species that are primarily dispersed by birds and secondarily dispersed by ants.

Implications of the results for current debates on tropical rain forest recruitment ecology: There is an increasing concern in tropical ecology about what are the ecological mechanisms determining the distribution of tropical tree species. The evidence gathered showed that secondary seed dispersal is a key mechanism determining seed and seedling survival by moving seeds away from the nearest conspecific adult tree. Masking unviable seeds among viable ones could be an important mechanism determining seed dynamics in tropical tree recruitment dynamics; if unviable seeds are produced in large numbers, then seed-masking effects away from the nearest conspecific D. oleifera tree species could lead to higher recruitment and thus could allow multiple tree species to coexist at low densities - the essence of the Janzen effect (Janzen 1970). A key mechanism contributing to the distribution of seedlings is arthropod herbivory, which was higher close to the nearest conspecific adult, where seedling density is high. The result suggests that bat seed dispersal and terrestrial vertebrate seed dispersal are necessary to escape arthropod herbivory associated with high seedling density. In conclusion, secondary seed dispersal and arthropod herbivory are mechanisms determining the distribution of seedling recruitment of $D$. oleifera. 


\section{ACKNOWLEDGMENT}

Financial support for this research came from two Block Grants from the Department of Ecology and Evolutionary Biology of the University of Michigan (UM) to Javier Ruiz; an individual fellowship from the International Institute of the UM to JR; an International Foundation for Science Grant (D-3939-1) to JR and the Rackham International Student Grant of the UM to JR. Idea Wild provided supplemental support to JR. John Vandermeer, Paul Foster and Sandra Yap provided valuable comments to early versions of the manuscript. We are thankful to the members of Proyecto Biodiversidad/URACCAN for their support in many ways.

\section{RESUMEN}

Presentamos evidencia de la contribución relativa de la dispersión primaria y secundaria de semillas en la suerte que corren las mismas y en el reclutamiento de plántulas de la especie de bosque húmedo tropical Dipteryx oleifera. Este estudio fue realizado en una parcela permanente de 6.37 ha en la que semillas y plántulas del cohorte del 2007 fueron localizadas y mapeadas. Etiquetamos 2814 semillas para evaluar su suerte un año después de la germinación. Encontramos que la dispersión primaria por murciélagos libera a las semillas de la depredación bajo la copa del árbol adulto causada por la fase larval de un insecto. Los murciélagos dispersan semillas bajo la copa de palmas usadas como comederos, localizados a $40.94 \pm 1.48 \mathrm{~m}$ del árbol de $D$. oleifera más cercano y vertebrados terrestres congregaran las semillas en caches localizados aproximadamente a $41.90 \pm 2.43 \mathrm{~m}$ del árbol de $D$. oleifera. Un modelo proporcional de riesgos fue ajustado a los datos de semillas y los resultados sugieren que la dispersión decrece la probabilidad de mortalidad de las semillas $1.16 \%$ por cada metro del árbol conspecífico más cercano $(\mathrm{p}<0.001)$ y la dispersión secundaria de semillas decrece la probabilidad de mortalidad $23.94 \%$ por cada metro $(p<0.001)$. Los modelos de regresión de quebrados muestran que las semillas inviables reducen la tasa de depredación de las viables. Por cada semilla inviable depositada por los murciélagos en las agrupaciones de semillas, la tasa de depredación por vertebrados terrestres decreció $6 \%(\mathrm{p}<0.001)$. Por cada semilla dañada por vertebrados en las agrupaciones, la tasa de germinación decreció 4\% $(\mathrm{p}<0.001)$. Por cada semilla germinada en las agrupaciones, la tasa de reclutamiento incrementó $16 \%(\mathrm{p}=0.000)$. La sobrevivencia de plántulas con dispersión secundaria fue estadísticamente diferente a la de aquellas que únicamente tuvieron dispersión primaria $(\mathrm{F}=0.153, \mathrm{p}=0.697, \mathrm{df}=1.98)$. Ambos tipos de dispersión contribuyeron con una alta sobrevivencia de plántulas lejos del árbol congénere más cercano $\left(\mathrm{r}^{2}=0.713, \mathrm{n}=578\right.$, $\mathrm{p}=0.004)$. Concluimos que la distribución de las plántulas de D. oleifera es consistente con la Hipótesis de JanzenConnell y depende de la dispersión primaria por murciélagos, dispersión secundaria por vertebrados terrestres, el efecto de enmascaramiento y el constante ataque de insectos herbívoros a las plántulas.

\section{REFERENCES}

Arias-Le Claire, H. 2001. Remoción y germinación de semillas de Dipteryx panamensis y Carapa guianensis en bosques fragmentados de Sarapiquí, Costa Rica. Rev. Fore. Centroamericana 34: 42-46.

Asquit, N.M., J. Terborgh, E.A. Arnold \& C.M. Riveros. 1999. The fruits that agouti ate: Hymenea courbaril seed fate when its diperser is absent. J. Trop. Ecol. 15: 229-235.

Augspurger, C.K. 1983. Seed dispersal of the tropical tree, Platypodium elegans, and the escape of its seedlings from fungal pathogens. J. Ecol. 71: 759-771.

Bawa, K.S., D.R. Perry \& J.H. Beach. 1985. Reproductive Biology of Tropical Lowland Rain Forest Trees. I. Sexual Systems and Incompatibility Mechanisms Am. J. Bot. 72: 331-345.

Becker, P., M. Leighton \& J.B. Payne. 1985. Why tropical squirrels carry seeds out of the source crowns. J. Trop. Ecol. 1: 183-186.

Boinski, S. \& R.M. Timm. 1985. Predation by squirrel monkeys and double-toothed kites on tent-making bats. Am. J. Primatology 9: 121-127.

Bonaccorso, F.J., W.E. Glanz \& C.M. Sandford. 1980. Feeding assemblages of mammals at fruiting Dipteryx panamensis (Papilionaceae) trees in Panama: seed predation, dispersal, and parasitism. Rev. Biol. Trop. 28: 61-72.

Boucher, H.D. 1981. Seed predation by mammals and forest dominance by Quercus oleoides, a tropical lowland oak. Oecologia 49: 409-414.

Cintra, R. \& V. Horna. 1997. Seed and seedling survival of the palm Astrocaryum murumuru and the legume tree Dipteryx micrantha in gaps in Amazonian forest. J. Trop. Ecol. 13: 257-277.

Clark, D.A. \& D.B. Clark. 1984. Spacing dynamics of a tropical rain forest tree: evaluation of the JanzenConnel model. Am. Nat. 124: 769-788. 
Clark, D.A. \& D.B. Clark. 1992. Life history diversity of canopy and emergent trees in a neotropical rain forest. Ecol. Monog. 62: 315-344.

Clark, D.B. \& D.A. Clark. 1985. Seedling dynamics of a tropical tree: impacts of herbivory and meristem damage. Ecology 66: 1884-1892.

Clark, D.B. \& D.A. Clark. 1987. Population ecology and microhabitat distribution of Dipteryx panamensis a neotropical rain forest tree. Biotropica 19: 236-244.

Clark, D.B., D.A. Clark \& P.M. Rich. 1993. Comparative analysis of micohabitat utilization by saplings of nine tree species in neotropical rain forest. Biotropica 25: 395-407.

Clark, J.S., M.R. Silman, R. Kern, E. Macklin \& J. HilleRis-Lambers. 1999. Seed dispersal near and far: patterns across temperate and tropical forests. Ecology 80: $1475-1494$.

Condit, R., S.P. Hubbell \& R.B. Foster 1995. Mortality rates of 205 neotropical tree and shrub species and the impact of a severe drought. Ecol. Monog. 65: 419-439.

Connell, J.H. 1971. On the roles of natural enemies in preventing competitive exclusion in some marine animals and in rain forest, p. 298-312. In P.J. Den Boer \& G.R. Grandwell (eds.). Proceedings of the Advanced Study Institute on Dynamics of Numbers in Population. Oosterbeek, Wageningen, Holland.

Cox, D.R. \& D. Oakes. 1984. Analysis of survival data. Chapman \& Hall, London, UK.

DeMattia, E.A., L.M. Curran \& B.J. Rathcke. 2004. Effects of small rodents and large mammals on neotropical seeds. Ecology 85: 2161-2170.

Eichhorn, M.P., S.G. Compton \& S.E. Hartley. 2006. Seedling species determines rates of leaf herbivory in a Malaysian rain forest. J. Trop. Ecol. 22: 513-519.

Faraway, J.J. 2005. Extending the Linear models with R. Chapman \& Hall, Minsesota, USA.

Forget, P.M. 1990. Seed-dispersal of Vouacapoua americana (Caesalpiniaceae) by caviomorph rodents in French Guyana. J. Trop. Ecol. 6: 459-468.

Forget, P.M. 1992. Seed removal and seed fate in Gustavia superba (Lecythidaceae). Biotropica 24: 408-414.

Forget, P.M. 1993. Post-dispersal predation and scatterhoarding of Dipteryx oleifera (Papilionacea) seeds by rodents in Panama. Oecologia 94: 255-261.
Forget, P.M. \& D. Wenny. 2005. How to elucidate seed fate? A review of methods used to study seed removal and secondary seed dispersal, p. 379-393. In P.M. Forget, J.E. Lambert, P.E. Hulme \& S.B. Vander Wall (eds.). Seed fate predation, dispersal and seedling establishment. CABI, Wallingford, UK.

Forget, P.M. \& T. Milleron. 1991. Evidence for secondary seed dispersal by rodents in Panama. Oecologia 87: 596-599.

Granzow-de la Cerda, I., N. Zamora, J.H. Vandermeer \& D.H. Boucher. 1997. Biodiversidad de especies arbóreas en el bosque tropical húmedo del Caribe Nicaragüense siete años después del huracán Juana. Rev. Biol. Trop. 45: 1409-1419.

Guariguata, M.R., H. Arias-Le Claire \& G. Jones. 2002. Tree seed fate in a logged and fragmented forest landscape, Northeastern Costa Rica. Biotropica 34: 405-415.

Hanson, T., S. Brunsfeld \& B. Finegan. 2006. Variation in seedling density and seed predation indicators for the emergent tree Dipteryx panamensis in continous and fragmented rain forest. Biotropica 38: 770-774.

Howe, H.F. \& M.N. Miriti. 2000. No question: seed dispersal matters. Tree 15: 434-436.

Howe, H.F. \& M.N. Miriti. 2004. When seed dispersal matters. Bioscience 54: 651-660.

Howe, H.F. \& J. Smallwood. 1982. Ecology of seed dispersal. Ann. Rev. Ecol. Syst. 13: 201-228.

IRENA. 1991. Diagnóstico de los recursos naturales no renovables. In Generalidades sobre la Costa Atlántica. Internal Report, Instituto de Recursos Naturales de Nicaragua (IRENA), Nicaragua. Vol. 2: 9-14.

Jansen, P.A., F. Bongers \& H.H.T.P. Prins. 2006. Tropical rodents change rapidly germinating seeds into longterm food supplies. Oikos 113: 449-458.

Janzen, D.H. 1970. Herbivores and the number of tree species in tropical forest. Am. Nat. 104: 501-528.

Janzen, P.A., F. Nongers \& L. Hemerik. 2004. Seed mass and mast seedling enhance dispersal by a neotropical scatter-hoarding rodent. Ecol. Monog. 74: 569-589.

LaVal, R.K. \& H.B. Rodríguez. 2002. Mamíferos de Costa Rica. INBio, Santo Domingo de Heredia, Costa Rica.

McClearn, D., J. Kohler, K.J. McGowan, E. Cedeno, L.G. Carbone \& D. Miller. 1994. Arboreal and terrestrial mammals trapping on Gigante Peninsula, Barro Colorado Nature Monument, Panama. Biotropica 26: $208-213$. 
Moore, P.D. 1997. Feeding patterns on forest floors. Nature 390: 231-231.

Ouden, J.D., P.A. Jansen \& R. Smith. 2005. Jay, mice and oaks: predation and dispersal of Quercus robur and Q. petraea in North-western Europe, p. 223-240. In P.M. Forget, J.E. Lambert, P.E. Hulme \& S.B. Vander Wall (eds.). Seed fate predation, dispersal and seedling establishment. CABI, Wallingford, UK.

Perry, D.R. \& A. Starrett. 1980. The pollination ecology and blooming strategy of a neotropical emergent tree, Dipteryx pamamensis. Biotropica 12: 307-313.

Reid, F. 1997. A field guide to the mammals of Central America and Southeast Mexico. Oxford University, New York, USA.

Ruiz, J., D.H. Boucher, C.L. Ingram-Flores \& L.F. Chaves. 2009a. Beneficial effect of spider presence on seedling recruitment of the neotropical tree Dipteryx oleifera (Fabaceae). Rev. Biol. Trop. 57: 837-846.

Ruiz, J. \& H.D. Boucher. 2008. Recruitment of Dipteryx oleifera Benth (Fabaceae) correlates with bat seed dispersal, rodent seed dispersal and roosting palm species away from conspecific trees. Brenesia 70: $1-9$.

Ruiz, J., H.D. Boucher, D. Ruiz-Moreno \& C. IngramFlores. 2009b. Recruitment dynamics of the tropical rainforest tree Dipteryx oleifera (Fabaceae) in Eastern Nicaragua. Rev. Biol. Trop. 57: 321-338.

Russo, S.E. 2005. Linking seed fate to natural dispersal patterns: factors affecting predation and scatterhoarding of Virola calophylla seeds in Peru. J. Trop. Ecol. 21: 243-253.

Sautu, A., J.H. Baskin, C.C. Baskin \& R. Condit. 2006. Studies on the seed biology of 100 species of trees in a seasonal moist tropical forest, Panama, Central America. For. Ecol. Man. 234: 245-263.

Vander Wall, S.B., K.M. Kuhn \& M.J. Beck. 2005. Seed removal, seed predation, and secondary dispersal. Ecology 86: 801-806.

Witt, E. 2001. Seed dispersal by small terrestrial mammals in shade coffee farms in Chiapas, Mexico. M.Sc. Thesis, University of Michigan, USA. 